\title{
Synaptic Activity Modulates the Induction of Bidirectional Synaptic Changes in Adult Mouse Hippocampus
}

\author{
Anaclet Ngezahayo, ${ }^{1}$ Melitta Schachner, ${ }^{1,2}$ and Alain Artola ${ }^{1}$ \\ ${ }^{1}$ Department of Neurobiology, Swiss Federal Institute of Technology Zürich, Hönggerberg, $\mathrm{CH}-8093$ Zürich, Switzerland, \\ and 2Zentrum für Molekulare Neurobiologie, Universität Hamburg, D-20246 Hamburg, Germany
}

Activity-dependent synaptic plasticity is critical for learning and memory. Considerable attention has been paid to mechanisms that increase or decrease synaptic efficacy, referred to as longterm potentiation (LTP) and long-term depression (LTD), respectively. It is becoming apparent that synaptic activity also modulates the ability to elicit subsequent synaptic changes. We provide direct experimental evidence that this modulation is attributable, at least in part, to variations in the level of postsynaptic depolarization required for inducing plasticity. In slices from adult hippocampal CA1, a brief pairing protocol known to produce LTP can also induce LTD. The voltage-response function for the induction of LTD and LTP in naive synapses exhibits three parts: at a postsynaptic membrane potential during pairing $\left(V_{\mathrm{m}}\right) \leq-40 \mathrm{mV}$, no synaptic modification is obtained; at $V_{\mathrm{m}}$ between -40 and $-20 \mathrm{mV}$, LTD is induced; and, finally, at $V_{\mathrm{m}}>$

Long-lasting, activity-dependent changes in synaptic efficacy are likely to underlie fundamental neural processes, including neural development and information storage. Two opposite forms of activity-dependent synaptic modifications have been identified so far, long-term potentiation (LTP) and long-term depression (LTD). In many brain areas including the hippocampus (but not synapses between mossy fibers and CA3 neurons; for review, see Nicoll and Malenka, 1995) and neocortex, the direction and the degree of the synaptic change are functions of postsynaptic depolarization; LTD is obtained after low levels of postsynaptic depolarization, whereas LTP is produced by a stronger depolarization (Dunwiddie and Lynch, 1978; Artola et al., 1990; Dudek and Bear, 1992; Kirkwood et al., 1993, Mayford et al., 1995).

It is becoming apparent that the induction of a synaptic change is also sensitive to the state generated by previous pattern of presynaptic and postsynaptic activity. The activity-dependent modulation of subsequent synaptic plasticity has been termed "metaplasticity" (Abraham and Bear, 1996; Abraham and Tate, 1997). Metaplasticity can be observed physiologically as a persistent modification in the direction or degree of the synaptic change elicited by a given pattern of synaptic activation. In hippocampus,

Received Sept. 22, 1999; revised Jan. 3, 2000; accepted Jan. 12, 2000.

This work was supported by grants from the Swiss National Science Foundation (to A.A.), the Swiss Federal Institute of Technology Zürich (to A.A. and M.S.), and the Deutsche Forschungsgemeinschaft (to M.S.). We thank Drs. P. Ascher and V. Guenard for valuable comments on a previous version of this manuscript.

Correspondence should be addressed to Dr. Alain Artola at his present address: Rudolf Magnus Institute for Neurosciences, Universiteitsweg 100, 3584 CG Utrecht, The Netherlands. E-mail: a.artola@med.uu.nl.

Dr. Ngezahayo's present address: Institut für Biophysik, Universität Hannover, Herrenhauserstrasse 2, D-30419 Hannover, Germany.

Copyright $\odot 2000$ Society for Neuroscience $0270-6474 / 00 / 202451-08 \$ 15.00 / 0$
$-20 \mathrm{mV}$, LTP is generated. This function varies with initial synaptic efficacy. In depressed synapses, $\Theta^{-}$, the $V_{m}$ above which LTD is generated, is shifted toward more depolarized $V_{\mathrm{ms}}$ and $\Theta^{+}$, the LTD-LTP crossover point or, equivalently, the $V_{m}$ above which LTP is induced, toward more polarized $V_{\mathrm{ms}}$. Conversely in potentiated synapses, $\Theta^{-}$is shifted toward more polarized $V_{\mathrm{ms}}$. Therefore synaptic activity changes synaptic efficacy and accordingly adjusts the voltages for eliciting subsequent synaptic modifications. The concomitant shifts in the voltages for inducing LTD and LTP in opposite directions promote synaptic potentiation and inhibit synaptic depression in depressed synapses and vice versa in potentiated synapses.

Key words: long-term potentiation; long-term depression; activity-dependent modulation of LTD-LTP induction; hippocampus; CA1; mouse previous synaptic activity, whether it results in LTP (Barrionuevo et al., 1980; Staubli and Lynch, 1990; Fujii et al., 1991; Larson et al., 1993; Bortolotto et al., 1994; O’Dell and Kandel, 1994; Wagner and Alger, 1995), short-term potentiation (STP) (Wexler and Stanton, 1993), or no synaptic modification (Christie and Abraham, 1992; Wang et al., 1998), appears to facilitate subsequent LTD induction. Previous synaptic activity may also inhibit subsequent LTP induction. In hippocampus, LTP cannot be induced when the slices are bathed in either nominally $\mathrm{Mg}^{2+}$ free medium (Coan et al., 1989) or low concentrations of NMDA (Izumi et al., 1992a,b). Similarly, synaptic activation, for instance weak tetani that have no or very little effect on synaptic transmission, may decrease or even suppress subsequent induction of LTP by a strong tetanus (Fujii et al., 1991; Christie and Abraham, 1992; Huang et al., 1992). There are also examples of facilitation of LTP induction after either synaptic activation (Cohen and Abraham, 1996) or bath application of an agonist of metabotropic glutamate (mGlu) receptors (Bortolotto et al., 1994; Cohen and Abraham, 1996; Cohen et al., 1998). These results suggest that the minimum levels of postsynaptic depolarization or thresholds for the induction of LTD and LTP be influenced by previous synaptic activity. However, direct evidence in support of this idea is lacking. Moreover, it is not known how the LTD and LTP thresholds will be affected when challenged under similar conditions.

To address these questions, we used the whole-cell patch-clamp recording technique. We developed a brief pairing protocol to induce LTD, as well as LTP, in the CA1 region of adult hippocampus and examined the voltage-response function for the induction of LTD and LTP with this brief pairing in naïve and previously depressed and potentiated synapses. 


\section{MATERIALS AND METHODS}

Adult mice (2 months old) were deeply anesthetized with mask-applied ether- $\mathrm{O}_{2}$. Then, the animals were heart-perfused with $\sim 3 \mathrm{ml}$ of chilled modified artificial CSF (ACSF), and their brains were removed and immersed into chilled modified ACSF. Using a vibroslice, $350-\mu \mathrm{m}$-thick slices were cut in the horizontal plane. The slices were allowed to recover for at least $1 \mathrm{hr}$. They were then transferred to a recording chamber in which they were submerged in modified ACSF ( $\mathrm{pH} 7.4 ; 310-320 \mathrm{mOsm} /$ $\mathrm{kg}$ ) containing (in mM): $125 \mathrm{NaCl}, 26 \mathrm{NaHCO}_{3}, 2.5 \mathrm{KCl}, 1.25 \mathrm{NaH}_{2} \mathrm{PO}_{4}$, $2 \mathrm{CaCl}_{2}, 2 \mathrm{MgSO}_{4}$, and 25 glucose, saturated with $95 \% \mathrm{O}_{2}-5 \% \mathrm{CO}_{2}$. During the initial part of the experiment (perfusion, cutting), the $\mathrm{NaCl}$ in the modified ACSF was replaced by equimolar sucrose (215 mM). DL-2-Amino-5-phosphonopentanoic acid (AP-5) (Sigma, St. Louis, MO) was kept in concentrated stock solutions, which were diluted in ACSF and then bath applied. Experiments were performed at room temperature.

Standard whole-cell patch-clamp technique was used. One or two independent pathways were stimulated $(0.07 \mathrm{~Hz}$; pulse duration, 100 $\mu \mathrm{sec})$ using bipolar stainless steel electrodes placed in the stratum radiatum, equidistant from the pyramidal cell layer on each side of the recorded cell. In most of the experiments, stimuli of each pathway were paired within a delay of $50 \mathrm{msec}$. During conditioning, afferent stimulation at $2 \mathrm{~Hz}$ for $50 \mathrm{sec}$ was paired with various postsynaptic membrane depolarization. The patch electrodes (3-8 $\mathrm{M} \Omega$ ) were filled with an internal solution ( $\mathrm{pH} 7.3 ; 295-305 \mathrm{mOsm} / \mathrm{kg}$ ) containing (in mM): 135 K-gluconate, $5 \mathrm{NaCl}, 2 \mathrm{MgCl}_{2}, 10 \mathrm{HEPES}, 0.2$ EGTA, $2.5 \mathrm{Na}_{2} \mathrm{ATP}, 0.2$ $\mathrm{Na}_{3} \mathrm{GTP}$, and 10 sucrose. Series and input resistances were monitored throughout each experiment. Cells were excluded from data analysis if $>10 \%$ change in series or input resistances occurred during the course of the experiment. In addition, $I-V$ curves were performed before and after each pairing.

Data were collected with an Axopatch-1D (Axon Instruments, Foster City, CA) filtered at $1 \mathrm{kHz}$ and sampled at $5 \mathrm{kHz}$ using an ITC 16 interface (Instrutech Corp., New York, NY) and the software Pulse Pulsefit (Heka Elektronik, Lambrecht/Pfalz, Germany). The amplitude of EPSCs was measured by taking the average of a 2-3 msec window around the peak of the EPSC relative to the baseline. The data were normalized to the averaged value obtained during the $10 \mathrm{~min}$ period before applying the pairing protocol. To test whether a pairing had a significant effect on EPSC, a paired $t$ test was used in which the baseline responses were compared with response magnitude ( 5 min window) at 30 min (unless otherwise stated) after pairing. To compare either paired and unpaired pathways or different experimental manipulations, we used a paired and an unpaired $t$ test, respectively, with the same time window as described above. All averages are listed as mean \pm SEM.

\section{RESULTS}

Voltage-response function for the induction of LTD and LTP in naive synapses: induction of LTD with a brief pairing in adult hippocampal CA1

LTD has already been obtained with the whole-cell patch-clamp recording technique. It usually requires an afferent stimulation lasting several minutes (in cultured hippocampal neurons: Goda and Stevens, 1996; Deisseroth et al., 1996; Fitzsimonds et al., 1997) (in hippocampal slices from immature animals: Bolshakov and Siegelbaum, 1994; Oliet et al., 1997). However, brief pairings can also result in the induction of large LTD in slices from immature animals (Cummings et al., 1996; Wang et al., 1996, 1998; Kandler et al., 1998). Therefore, using the whole-cell patchclamp recording technique, we first tested whether a brief LTPinducing pairing could be converted into a LTD-inducing pairing in slices from adult hippocampus by decreasing the potential $\left(V_{\mathrm{m}}\right)$ at which the postsynaptic CA1 neuron is held during pairing. Pairing synaptic stimulation at $2 \mathrm{~Hz}$ for $50 \mathrm{sec}$ with postsynaptic membrane depolarization to $0 \mathrm{mV}$ induced LTP $(245.2 \pm 25 . \%$ of baseline, mean $\pm \mathrm{SEM}, p<0.01, n=6$ ) (Fig. 1a), which was prevented when the NMDA receptor antagonist DL-AP-5 (200 $\mu \mathrm{M})$ was bath-applied during pairing $(102.8 \pm 2.3 \%$ of baseline, $n=3$ ) (data not shown). Pairing the same afferent stimulation with postsynaptic depolarization to $-10 \mathrm{mV}$, referred to as pair-

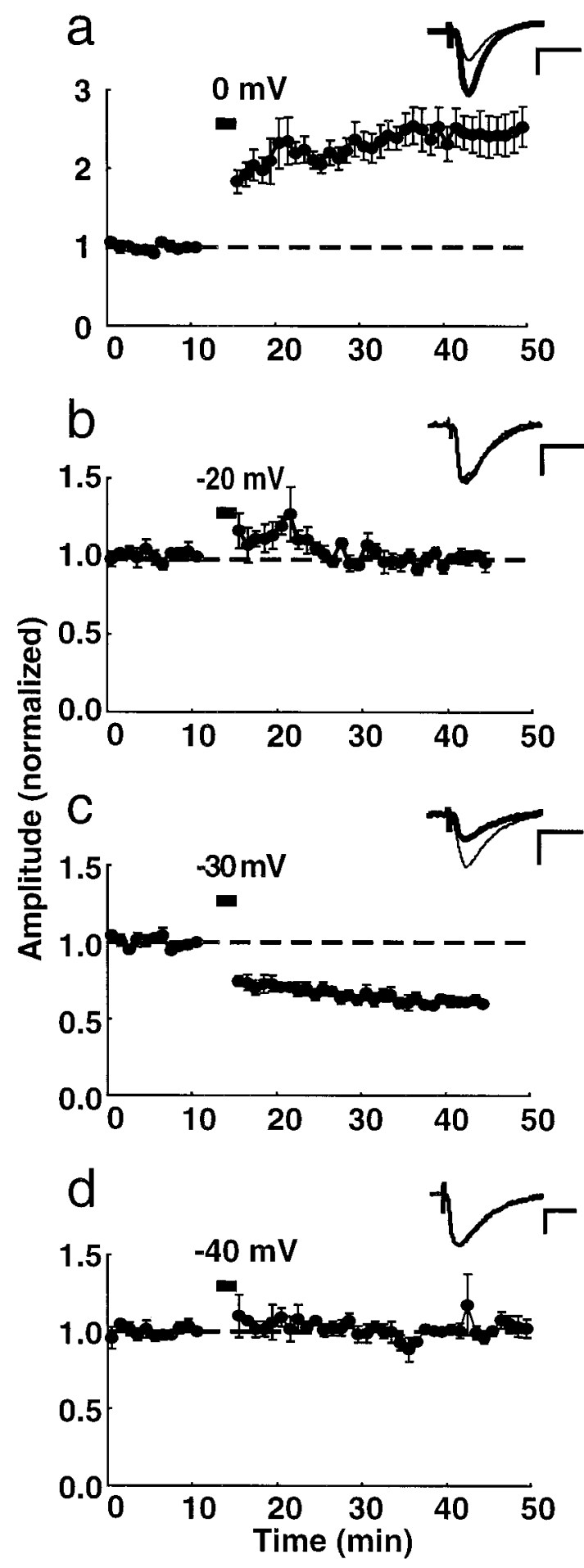

Figure 1. The direction of the synaptic modification depends on $V_{\mathrm{m}}$ during pairing. $a-d$, Summary graphs of whole-cell recordings in which synaptic stimulation $(2 \mathrm{~Hz}, 50 \mathrm{sec})$ was paired to $0 \mathrm{mV}(a ; n=6),-20 \mathrm{mV}$ $(b ; n=6),-30 \mathrm{mV}(c ; n=6)$, and $-40 \mathrm{mV}(d ; n=4)$. Superimposed averages of 10 successive evoked EPSCs recorded before (thin trace) and 30 min after (thick trace) pairing in representative cells. Calibration bars: $20 \mathrm{msec}, 50 \mathrm{pA}$.

ing to $-10 \mathrm{mV}$ in the remainder of the paper, also produced LTP, although its amplitude was lower $(162.2 \pm 13.8 \%$ of baseline, $p<$ $0.01, n=4$ ) (data not shown). Pairing to $-20 \mathrm{mV}$ had no 
long-term effect on synaptic responses $(99.9 \pm 3.1 \%$ of baseline, $n=6$ ) (Fig. 1b). In three of the six cells tested, this pairing resulted in STP (peak potentiation, $168.7 \pm 19.4 \%$ of baseline) that decayed to baseline within 10-15 min. On the other hand, pairing to $-30 \mathrm{mV}$ induced a very large depression $(60.2 \pm 1.9 \%$ of baseline, $p<0.01, n=6$ ) (Fig. 1c). Finally, pairing to $-40 \mathrm{mV}$ had no effect on synaptic responses $(103.8 \pm 4.7 \%$ of baseline, $n=4$ ) (Fig. $1 d$ ). To confirm that the induction of LTD with a brief pairing requires a minimum $V_{\mathrm{m}}$, two pairings, a first one to $-40 \mathrm{mV}$ and, $30 \mathrm{~min}$ later, a second one to $-30 \mathrm{mV}$, were applied to the same five cells (Fig. 2a). Although the first pairing had no effect on synaptic transmission $(104.7 \pm 5.0 \%$ of baseline $)$, the second one induced LTD $(63.8 \pm 2.3 \%$ of baseline, $p<0.01)$. It is important to note that the degree of depression was the same whether the pairing to $-30 \mathrm{mV}$ occurred $15-20 \mathrm{~min}$ (Fig. 1c) or 45-50 min (Fig. 2a) after the beginning of the recording (see cumulative distributions of the data in Fig. $2 b$ ). This confirms that the factors required for LTD induction do not dialyze out of the recorded neuron (Stevens and Wang, 1994).

These results show that LTD can be obtained in slices from adult hippocampus after a brief pairing protocol similar to that for LTP induction (see cumulative distributions of the data in Fig. $2 c$ ). The voltage-response function for the induction of LTD and LTP with a brief pairing in naive synapses is in Figure $2 d$. It exhibits three parts. For an afferent stimulation at $2 \mathrm{~Hz}$ for $50 \mathrm{sec}$, no synaptic modification is obtained when $V_{\mathrm{m}}$ is equal or more polarized than $-40 \mathrm{mV}\left(V_{\mathrm{m}} \leq-40 \mathrm{mV}\right)$. LTD is induced when $V_{\mathrm{m}}$ is more depolarized than $-40 \mathrm{mV}$ but more polarized than $-20 \mathrm{mV}\left(-40 \mathrm{mV}<V_{\mathrm{m}}<-20 \mathrm{mV}\right)$. Finally, LTP is generated when $V_{\mathrm{m}}$ is more depolarized than $-20 \mathrm{mV}\left(V_{\mathrm{m}}>-20 \mathrm{mV}\right)$. Thus, LTD induction requires a minimum $V_{\mathrm{m}}$. This confirms previous observations in neocortex and hippocampus that LTD induction requires a minimum cooperativity among afferents (Kerr and Abraham, 1995) and is prevented by hyperpolarizing the postsynaptic neuron (Artola et al., 1990; Mulkey and Malenka, 1992; Bolshakov and Siegelbaum, 1994; Deisseroth et al., 1996; Goda and Stevens, 1996; Fitzsimonds et al., 1997). The voltages that need to be reached for inducing LTP, referred to as voltages for inducing LTP in the remainder of the paper, are higher than those for inducing LTD. Interestingly, pairing to -20 $\mathrm{mV}$ did not produce any significant long-term modification of synaptic strength in either average cells (Fig. $1 b$ ) or in any of the examined cells (Fig. 2c). The $V_{\mathrm{m}}$ above which LTD is obtained ( $-40 \mathrm{mV}$ in naïve synapses) and the LTD-LTP crossover point or, equivalently, the $V_{\mathrm{m}}$ above which LTP is induced $(-20 \mathrm{mV}$ in naïve synapses), will be referred to as $\Theta^{-}$and $\Theta^{+}$, respectively, in the remainder of the paper.

To determine whether LTD induced in adult hippocampus with a brief pairing was input-specific, we used a second independent pathway that was not activated during pairing to $-30 \mathrm{mV}$. Only the pathway that was activated during pairing to $-30 \mathrm{mV}$ exhibited stable LTD ( $1 \mathrm{hr}$ after pairing: paired $57.9 \pm 2.0 \%$, unpaired $103.7 \pm 3.3 \%$ of baseline, $p<0.001, n=7$ ) (Fig. $3 a$ ). Synaptic depression developed slowly. After a 25-35\% initial reduction, the response further decreased to reach a final stable value 15-20 min after pairing. A similar slow development for LTD has been observed previously in hippocampal CA1 from immature animals using a brief induction protocol (Cummings et al., 1996; Wang et al., 1998). Two distinct forms of LTD induced with several minutes long, low-frequency stimulation (LFS), one dependent on the activation of NMDA receptors and the other one dependent on the activation of mGlu receptors, coexist in
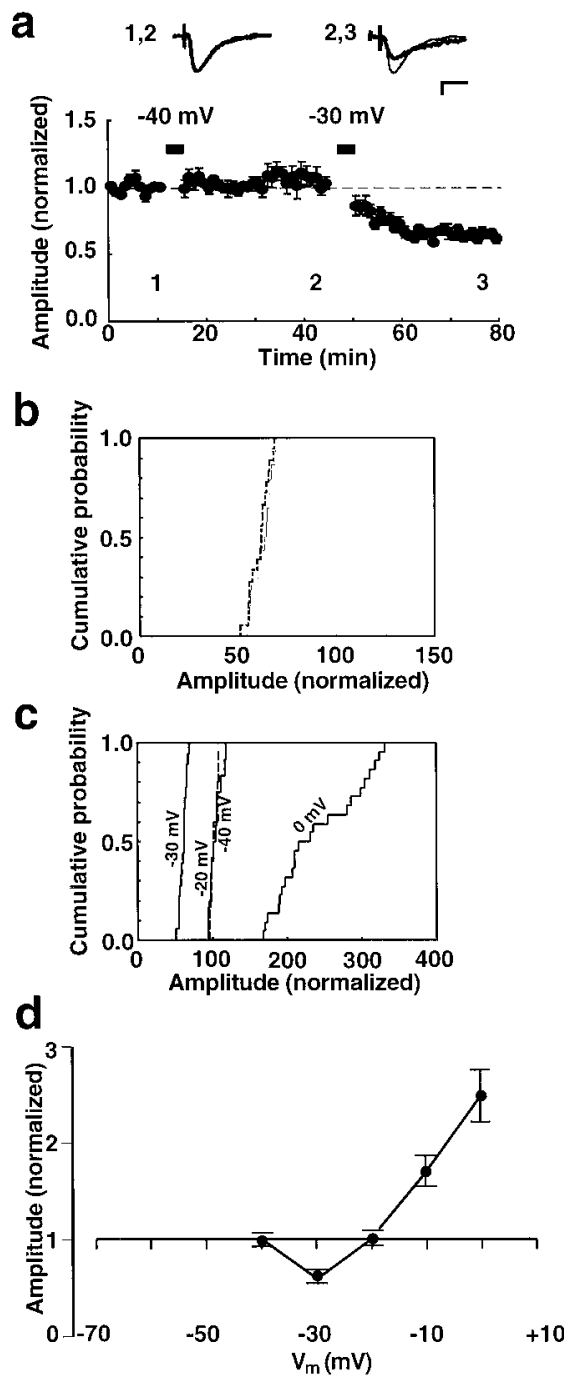

Figure 2. a, Summary graph of five whole-cell recordings in which synaptic stimulation was paired to $-40 \mathrm{mV}$ and $30 \mathrm{~min}$ later, to $-30 \mathrm{mV}$. Superimposed traces are averages of 10 successive evoked EPSCs recorded in a representative cell as indicated in the graph. Trace 1 is thin and trace 2 is thick in 1,2; trace 2 is thin and trace 3 is thick in 2,3. Calibration bars: $20 \mathrm{msec}, 50 \mathrm{pA}$. $b$, Cumulative histograms showing the effect of a pairing to $-30 \mathrm{mV}$ in every cell when pairing occurred before (solid line; $n=19$, including the results in Figs. 1c, 3a) and after (dotted line; $n=15$, including the results in Figs. $2 a, 3 b, 5 a$ ) the washout of LTP mechanisms. $c$, Cumulative histograms showing the effect of a pairing to $0 \mathrm{mV}(n=23$, including the results in Figs. $1 a, 6 a),-20 \mathrm{mV}$ (dotted line; $n=6$, including the results in Fig. $1 b),-30 \mathrm{mV}(n=19$, including the results in Figs. $1 c, 3 a)$, and $-40 \mathrm{mV}(n=13$, including the results in Figs. $1 d, 2 a, 5 a)$ in every cell when the pairing occurred before the washout of LTP mechanisms. $d$, Voltage-response function for the induction of LTD and LTP in naive synapses.

juvenile hippocampus (Oliet et al., 1997). To examine the pharmacology of LTD induced in the adult hippocampus with a brief pairing, we bath-applied the NMDA receptor antagonist DL-AP-5 $(200 \mu \mathrm{M})$ during pairing to $-30 \mathrm{mV}$. It completely abolished LTD (50 min after pairing: paired $103.1 \pm 2.1 \%$, unpaired $106.7 \pm$ $2.2 \%$ of baseline, $n=5$ ) (Fig. $3 b$ ). After washing out the AP-5, a second pairing to $-30 \mathrm{mV}$ produced an input-specific LTD (50 min after pairing: paired $58.7 \pm 2.4 \%$, unpaired $102.9 \pm 0.7 \%$ of baseline, $p<0.001)$. Therefore, LTD induced in adult hippocampus with a brief pairing is input-specific and NMDA receptor-dependent. 

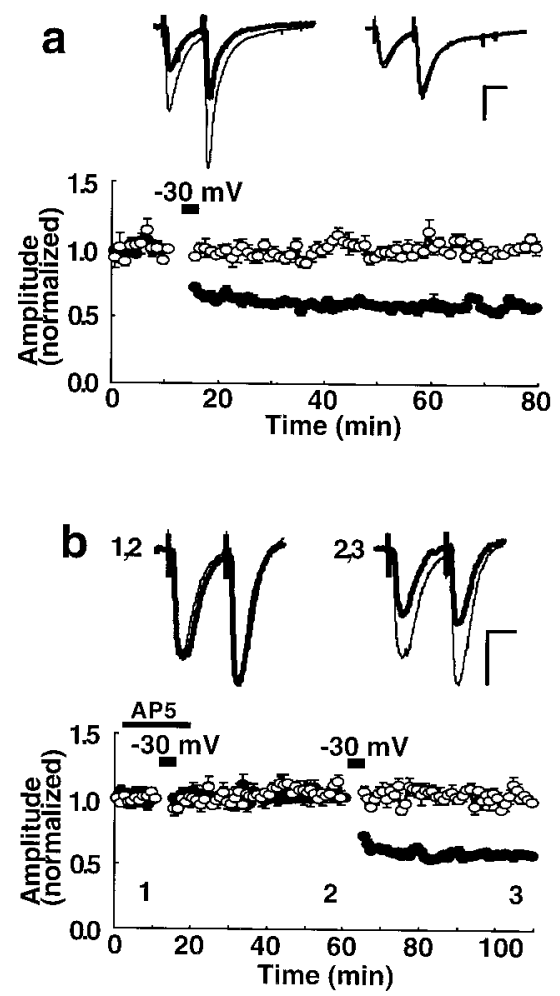

Figure 3. Induction of LTD in adult hippocampus with a brief pairing is input-specific and NMDA receptor-dependent. $a$, Summary graph of seven whole-cell recordings in which synaptic stimulation was paired to $-30 \mathrm{mV}$ in one pathway ( filled symbols). Superimposed traces are averages of 10 successive evoked (paired-pulse stimulation) EPSCs in paired (left) and unpaired (right) pathways recorded in a representative cell before (thin trace) and $60 \mathrm{~min}$ after (thick trace) pairing. $b$, Summary graph of five whole-cell recordings in which synaptic stimulation was paired to $-30 \mathrm{mV}$ in one pathway in the presence and after washing out of $200 \mu \mathrm{M} \mathrm{AP-5}$ ( filled symbols). Superimposed traces are averages of 10 successive evoked (paired-pulse stimulation) EPSCs in the paired pathway recorded in a representative cell as indicated in the graph. Trace 1 is thin and trace 2 is thick in 1,2; trace 2 is thin and trace 3 is thick in 2,3. Calibration bars: $20 \mathrm{msec}, 50 \mathrm{pA}$.

\section{Voltage-response function for the induction of LTD and LTP in depressed synapses}

To determine whether the voltage-response function for the induction of LTD and LTP varies in previously depressed synapses, we applied two successive pairings, a first or conditioning pairing to $-30 \mathrm{mV}$ to depress synapses and $10 \mathrm{~min}$ later a second or test pairing to various $V_{\mathrm{ms}}$. The second pairing had to occur within 20 min after the beginning of the recording to prevent the washout of LTP mechanisms. Pairing to $-20 \mathrm{mV}$ has no significant effect in naive synapses (see above). When such a pairing to $-20 \mathrm{mV}$ was applied $10 \mathrm{~min}$ after the conditioning pairing to -30 $\mathrm{mV}$, it produced a very large input-specific LTP (paired $213.4 \pm$ $17.4 \%$ of baseline, $p<0.01, n=6$; unpaired $98.5 \pm 2.9 \%$ of baseline, $n=3$ ) (Fig. $4 a$ ). Therefore, the conditioning pairing facilitated subsequent induction of LTP. To examine whether the effect of the conditioning pairing was input-specific, we simultaneously paired the two independent pathways to $-20 \mathrm{mV}$ during test pairing ( $n=3$ of the 6 cells). Only the conditioned pathway underwent LTP (Fig. 4a). Similar LTP was obtained when test pairing was to $-10 \mathrm{mV}(203.0 \pm 25.0 \%$ of baseline, $p<0.02, n=$ 5) (data not shown). On the other hand, test pairings to $-30 \mathrm{mV}$ (Fig. $4 b$ ) or to $-40 \mathrm{mV}$ (data not shown) produced an input-
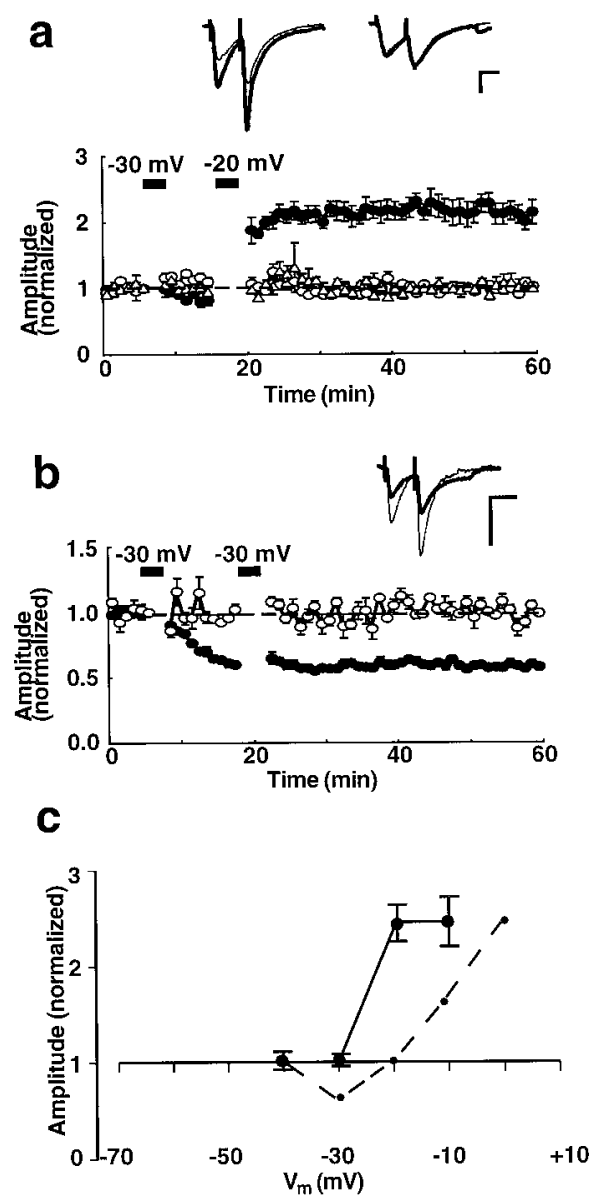

Figure 4. Voltage-response function for the induction of LTD and LTP in depressed synapses. $a$, Summary graphs of six whole-cell recordings in which synaptic stimulation was paired to $-30 \mathrm{mV}$ (conditioning pairing) and $10 \mathrm{~min}$ later to $-20 \mathrm{mV}$ (test pairing) in one pathway (-). Synaptic stimulation was either paired to $-20 \mathrm{mV}(\Delta ; n=3)$ or discontinued $(\bigcirc$; $n=3$ ) during test pairing in the second pathway. Superimposed traces are averages of 10 successive evoked (paired-pulse stimulation) EPSCs recorded in a representative cell before (thin trace) and 40 min after (thick trace) pairings to -30 and $-20 \mathrm{mV}$ in one pathway (left) and pairing to $-20 \mathrm{mV}$ in the other pathway (right). $b$, Summary graph of four whole-cell recordings in which synaptic stimulation was paired to $-30 \mathrm{mV}$, two times at $10 \mathrm{~min}$ interval, in one pathway ( filled symbols). Superimposed traces are as in $a$, left. Calibration bars: $20 \mathrm{msec}, 50 \mathrm{pA}$. $c$, Voltage-response function for the induction of LTD and LTP in depressed synapses, superimposed with the same function in naive synapses.

specific LTD (after test pairings to -30 and $-40 \mathrm{mV}: 60.5 \pm$ $1.6 \%$ of baseline, $p<0.01, n=4$; and $59.4 \pm 3.0 \%$ of baseline, $p<0.01, n=3$, respectively). The degree of depression was not different, however, from that obtained after a single pairing to $-30 \mathrm{mV}$.

To obtain the voltage-response function for the induction of LTD and LTP in previously depressed synapses, we computed the difference between the effect on synaptic strength of combinations of pairings and that of a single pairing to $-30 \mathrm{mV}$ (Fig. $4 c$ ). This function is very different from that in naive synapses. It exhibits only two parts; there is no synaptic modification at $V_{\mathrm{m}} \leq$ $-30 \mathrm{mV}$, whereas a very large LTP is obtained at $V_{\mathrm{m}}>-30 \mathrm{mV}$. Therefore, LTP is facilitated because $\Theta^{+}$is shifted toward a more polarized $V_{\mathrm{m}}$ (from -20 to $-30 \mathrm{mV}$ ). Interestingly, there is a plateau of potentiation and the maximum potentiation obtained after test pairings to $-20 \mathrm{mV}$, and $-10 \mathrm{mV}$ is the same as that 
a
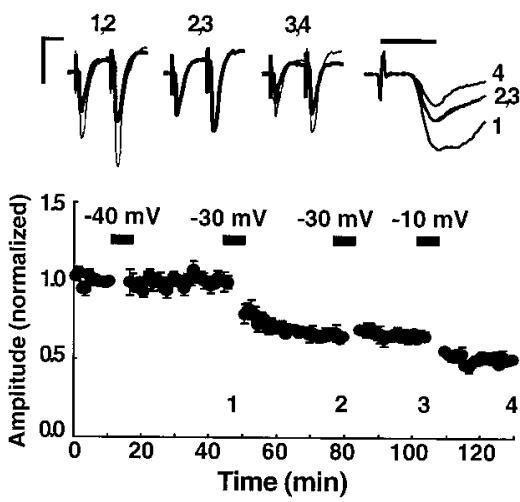

b

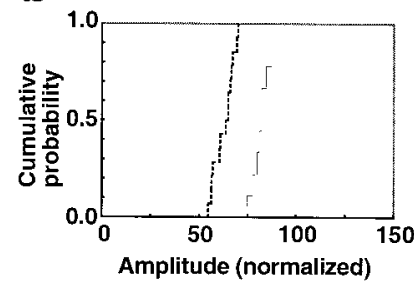

Figure 5. Induction of LTD in depressed synapses. $a$, Summary graph of four whole-cell recordings (different from those in Fig. $2 a$ ) in which synaptic stimulation was paired successively to $-40,-30,-30$, and -10 $\mathrm{mV}$. Superimposed traces are averages of 10 successive evoked (pairedpulse stimulation) EPSCs recorded in a representative cell as indicated in the graph. Trace 1 is thin and trace 2 is thick in 1,2; trace 2 is thin and trace 3 is thick in 2,3; trace 3 is thin and trace 4 is thick in 3,4. The traces are superimposed on the right at expanded time scale. Calibration bars: 20 and $10 \mathrm{msec}$ (expanded time scale), $50 \mathrm{pA} . b$, Cumulative histograms showing the effect of a pairing to $-30 \mathrm{mV}$ (after the washout of LTP mechanisms) in naive synapses (dotted line; $n=15$, including the results in Figs. $2 a, 3 b, 5 a$ ) and to $-10 \mathrm{mV}$ in previously depressed synapses (solid line; $n=10$, including the results in $a$ ) in every cell.

after a pairing to $0 \mathrm{mV}$ in naive synapses. This results in a steeper slope between no synaptic modification $\left(V_{\mathrm{m}}=-30 \mathrm{mV}\right)$ and maximum $\operatorname{LTP}\left(V_{\mathrm{m}}=-20 \mathrm{mV}\right)$. On the other hand, the voltage window for eliciting LTD has completely vanished. Synaptic strength could not be further decreased in previously depressed synapses.

\section{Induction of LTD in depressed synapses}

We assumed that the suppression of LTD in previously depressed synapses was not attributable to the saturation of LTD but to a shift toward more depolarized $V_{\mathrm{ms}}$ of the voltages for eliciting LTD. To examine this hypothesis, test pairings were now applied $30-40 \mathrm{~min}$ after conditioning to $-30 \mathrm{mV}$, i.e., after the response had stabilized and LTP induction was washed out. As observed previously before LTP washout, a test pairing to $-30 \mathrm{mV}$ had no effect in previously depressed synapses. On the other hand, a test pairing to $-10 \mathrm{mV}$ was able to further depress synaptic responses (from $63.4 \pm 1.7$ to $51.3 \pm 1.7 \%$ of pre-LTD baseline, $p<0.01$, $n=10$ ), thus indicating that, in previously depressed synapses, the voltages for inducing LTD are shifted to more depolarized $V_{\mathrm{ms}}$. Figure $5 a$ shows how successive pairings, in the same cells, progressively shift the voltages for inducing LTD above $-30 \mathrm{mV}$. It is important to note, however, that the degree of depression was smaller (approximately half of that obtained after a pairing to $-30 \mathrm{mV}$ in naive synapses) (see cumulative distribution of the data in Fig. 5b). Finally, an additional pairing to $0 \mathrm{mV}, 20-30 \mathrm{~min}$ after that to $-10 \mathrm{mV}$, had no further effect (from $51.9 \pm 3.4$ to $48.6 \pm 2.3 \%$ of pre-LTD baseline, $n=5$ ).

Therefore, the reason that further LTD could not be induced in previously depressed synapses was not because depression was saturated but rather because the voltages for inducing LTD were shifted toward more depolarized $\mathrm{V}_{\text {ms. }}$. This shift combined with that of the voltages for eliciting LTP in the opposite direction, i.e., toward more polarized $\mathrm{V}_{\mathrm{ms}}$, resulted in an overlap between the two voltage ranges for eliciting LTP and LTD. Interestingly, it appears that in these conditions the mechanisms for LTP overcome those for LTD because the relative amplitude of the potentiation obtained after the combination of pairings to -30 and $-20 \mathrm{mV}$ and -30 and $-10 \mathrm{mV}$ was similar to that after a single pairing to $0 \mathrm{mV}$ in naive synapses (Fig. 4c). In conclusion, in depressed synapses, $\Theta^{-}$and $\Theta^{+}$move toward each other and tend to merge, occluding the voltage window for LTD induction.

\section{Induction of LTD in potentiated synapses}

In previously depressed synapses, there is thus a shift toward more depolarized $V_{\mathrm{ms}}$ of the voltages for inducing LTD. The evidence in adult hippocampal CA1 that LFS can depress potentiated responses while producing little or no depression in naive synapses (Barrionuevo et al., 1980; Staubli and Lynch, 1990; Fujii et al., 1991; Larson et al., 1993; Wexler and Stanton, 1993; Bortolotto et al., 1994; O’Dell and Kandel, 1994; Wagner and Alger, 1995) suggests that, in potentiated synapses, on the other hand, the voltages for inducing LTD are shifted toward more polarized $V_{\mathrm{ms}}$. Therefore, we examined the effect of a pairing to $-40 \mathrm{mV}$ in previously potentiated synapses. Pairing to $-40 \mathrm{mV}$ has no effect in naïve synapses, whether it occurs 10-15 min (Figs. $1 d, 2 a)$ or $40 \min (106.9 \pm 4.9 \%$ of baseline, $n=3$ ) (data not shown) after the beginning of the whole-cell recording. A first pairing to $0 \mathrm{mV}$ produced LTP $(222.0 \pm 22.9 \%$ of baseline, $p<$ $0.01, n=7)$. Thirty-five minutes later, a second pairing to -40 $\mathrm{mV}$ now produced a large depression (to $128.7 \pm 10.9 \%$ of pre-LTP baseline, $p<0.01$ ) (Fig. $6 a$ ). When normalized to post-LTP baseline, the amplitude of the synaptic response amounted to $59.2 \pm 3.6 \%$ (Fig. $6 b$ ). The relative amplitude of LTP depotentiation-LTD was thus similar to that of LTD in naive synapses. In addition, there was no correlation between the degree of depression and that of the previous potentiation. This indicates that the potentiation and the LTP depotentiation-LTD are independent processes. To examine whether the effect of the conditioning pairing to $0 \mathrm{mV}$ on $\Theta^{-}$was input-specific, we simultaneously paired two independent pathways to $-40 \mathrm{mV}$ during the second (test) pairing ( $n=3$ of the 7 cells). The control pathway remained unchanged $(98.8 \pm 3.9 \%$ of baseline) (Fig. $6 a)$, whereas the potentiated pathway underwent LTD (in these three cells, $56.2 \pm 1.3 \%$ of post-LTP baseline). Therefore, the shift in $\Theta^{-}$was input-specific. This result also confirmed that a pairing to $-40 \mathrm{mV}$ had no effect in naïve synapse, even after a long delay after the beginning of the whole-cell recording. The shift in $\Theta^{-}$ amounted to $\sim 10 \mathrm{mV}$ because a pairing to $-50 \mathrm{mV}$ had no effect on potentiated synapses $(102.7 \pm 4.4 \%$ of post-LTP baseline, $n=$ 5) (Fig. 6b).

Although it is plausible that a variation in the voltages for inducing LTP also occurs after potentiation, this could not be demonstrated using a similar protocol because the induction of LTP washes out very quickly with whole-cell patch-clamp recording. In addition, pairing a cell a second time shortly after the first time (see below) would lead to variations of the degree of poten- 

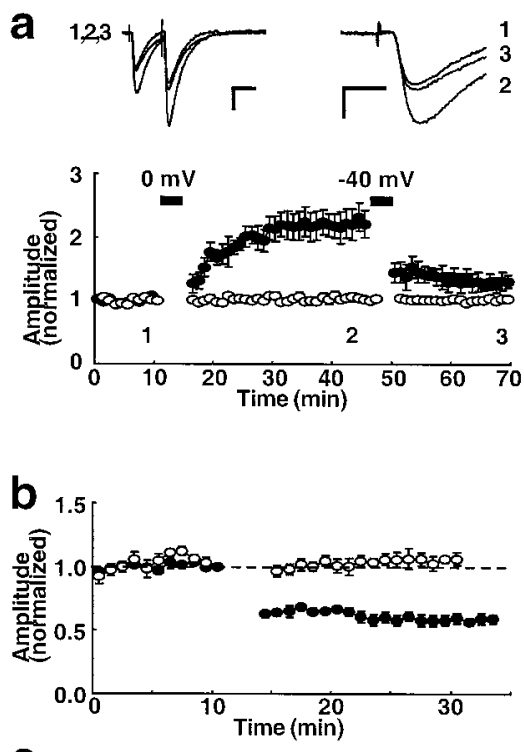

C

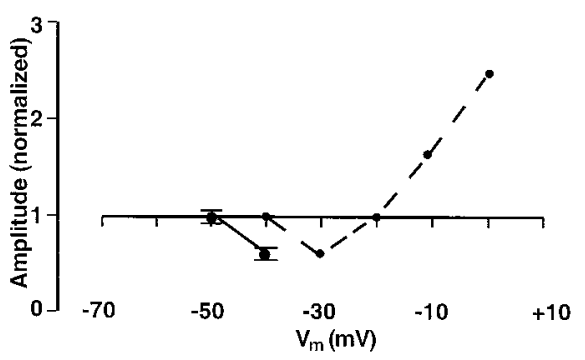

Figure 6. Induction of LTD is facilitated in potentiated synapses. $a$, Summary graph of seven whole-cell recordings in which synaptic stimulation was paired first to $0 \mathrm{mV}$ and $35 \mathrm{~min}$ later to $-40 \mathrm{mV}$ in one pathway (๑). In the second pathway $(\bigcirc ; n=3$ of the 7 cells), synaptic stimulation was only paired to $-40 \mathrm{mV}$ during the second pairing. Superimposed traces (expanded time and amplitude scales on the right) are averages of 10 successive responses to paired-pulse stimulation of the first pathway (paired successively to 0 and $-40 \mathrm{mV}$ ) recorded in a representative cell as indicated in the graph. Calibration bars: left, $20 \mathrm{msec}, 50 \mathrm{pA}$; right, 10 $\mathrm{msec}, 50 \mathrm{pA}$ ). $b$, Summary graph of the effect of a second pairing, $35 \mathrm{~min}$ after pairing to $0 \mathrm{mV}$. This second pairing was to $-40 \mathrm{mV}$ (0; cells in $a$ ) and to $-50 \mathrm{mV}(\bigcirc ; n=5)$. Amplitudes are normalized to the amplitude of synaptic responses just before this second pairing. $c$, Part of the voltage-response function for the induction of LTD and LTP in potentiated synapses, superimposed with the same function in naive synapses.

tiation, which are very difficult to interpret. As a consequence, Figure $6 c$ only shows part of the voltage-response function for the induction of LTD and LTP in previously potentiated synapses.

\section{DISCUSSION}

These results demonstrate that the voltages for inducing LTD and LTP vary with the initial level of synaptic efficacy of the involved connections. Specifically, we show that LTD and LTP can be induced in adult CA1 with a brief pairing protocol and that there is a continuum of voltage-response functions for the induction of LTD and LTP determined by initial synaptic efficacy. $\Theta^{-}$is progressively shifted toward more polarized $V_{\mathrm{ms}}(-20,-40$, and $-50 \mathrm{mV}$ in depressed, naïve, and potentiated synapses, respectively), whereas $\Theta^{+}$is shifted toward more depolarized $V_{\mathrm{ms}}(-30$ and $-20 \mathrm{mV}$ in depressed and naïve synapses, respectively), opening the voltage window for LTD induction, as initial synaptic

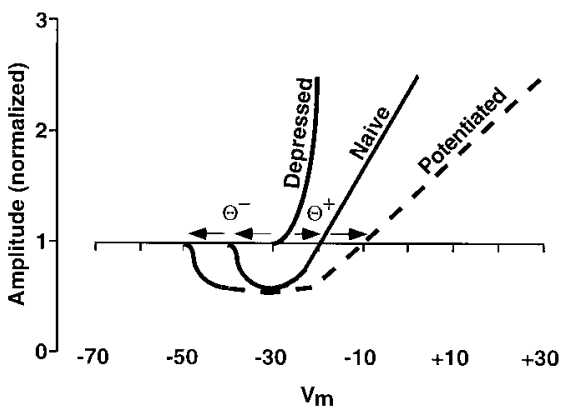

Figure 7. The voltage-response function for the induction of LTD and LTP varies with the initial state of the synapse. Superimposed voltageresponse curves for the induction of LTD and LTP in potentiated, naive, and depressed synapses. The putative part of the curve in potentiated synapses is shown with stripped lines. From depressed to potentiated synapses, $\Theta^{-}$and $\Theta^{+}$slide away from each other (arrows), progressively opening the voltage window for LTD induction.

strength increases and, vice versa, as it decreases (Fig. 7). These concomitant shifts in the $V_{\mathrm{ms}}$ for inducing LTD and LTP in opposite directions account well for the facilitation of synaptic potentiation and inhibition of synaptic depression in depressed synapses and vice versa in potentiated synapses.

\section{Synaptically induced LTD in adult CA1}

A brief pairing similar to that producing LTP can induce a robust NMDA receptor-dependent LTD in slices from adult hippocampal CA1 kept under normal conditions, i.e., $\mathrm{Ca}^{2+} / \mathrm{Mg}^{2+}$ ratio of one and normal synaptic inhibition. The potential role of LTD as a memory mechanism has been questioned because prolonged LFS produced reliable LTD only in slices obtained from immature (2-4 weeks old) animals and in cultured hippocampal neurons (Mulkey and Malenka, 1992; Dudek and Bear, 1993; Mayford et al., 1995). Evidence that LTD can be induced in slices from adult (several months old) hippocampus either synaptically after LFS when the $\mathrm{Ca}^{2+} / \mathrm{Mg}^{2+}$ ratio is increased (Dunwiddie and Lynch, 1978; Dudek and Bear, 1992, 1993; Norris et al., 1996) and synaptic inhibition is relieved (Wagner and Alger, 1995), or chemically after a short bath application of NMDA (Kamal et al., 1999), strongly suggest that the mechanisms underlying LTD expression are present in adult hippocampus. Recently, LTD has been obtained in the CA1 region of anesthetized (Heynen et al., 1996) and freely moving adult rats (Manahan-Vaughan, 1997). We provide evidence that, in hippocampal CA1, as in many other brain areas (for review, see Linden, 1994), LTD can be obtained in slices from adult tissue kept under normal conditions. The depression that we have obtained in adult animals after a brief pairing has the same amplitude as that produced in immature animals by LFS.

\section{Voltage-response function for the induction of LTD and LTP in naive synapses}

The finding that LTD and LTP can be obtained by pairing the same brief afferent stimulation with different $V_{\mathrm{ms}}$ provides direct evidence for the theoretical assumption that there is a continuum of associative synaptic changes determined by the level of postsynaptic depolarization during synaptic activity (Sejnowski, 1977; Bienenstock et al., 1982). However, as in the adult visual cortex (Artola et al., 1990), no synaptic modification is obtained at the most polarized $V_{\mathrm{ms}}\left(V_{\mathrm{m}} \leq-40 \mathrm{mV}\right)$.

Pairing to $-20 \mathrm{mV}$, too, produced no long-term synaptic modification. From our results, we cannot absolutely determine 
whether this lack of long-term synaptic modification was real or resulted from a balance between depression and potentiation. Nevertheless, the observed very little, if any, variation of the data (see cumulative distribution of the data in Fig. $2 c$ ) suggests that there was actually no long-term synaptic modification. As one depolarizes the postsynaptic neuron from $V_{\mathrm{m}}=-40 \mathrm{mV}$, there would be an increasing and then a decreasing probability for inducing LTD, followed by an increasing probability for LTP. In half of the cells, however, pairing to $-20 \mathrm{mV}$ produced STP. The voltages for inducing STP would thus be between those for eliciting LTD and LTP. This is consistent with the observation that a brief tetanic stimulation that routinely elicits STP induces LTD if cells are prevented from depolarizing (Cummings et al., 1996).

\section{Modulation of the voltage-response function for the induction of LTD and LTP by previous activity}

Modulation of subsequent induction of LTD and LTP by synaptic activity is attributable, at least in part, to changes in the voltages for inducing these two phenomena. In depressed synapses, $\Theta^{+}$is shifted toward a more polarized $V_{\mathrm{m}}$, from -20 to $-30 \mathrm{mV}$, and $\Theta^{-}$toward a more depolarized $V_{\mathrm{m}}$, from -40 to $-20 \mathrm{mV}$. Conversely, in potentiated synapses, $\Theta^{-}$is shifted toward a more polarized $V_{\mathrm{m}}$, from -40 to $-50 \mathrm{mV}$. $\Theta^{+}$could not be determined in potentiated synapses using the same protocol.

In both depressed and potentiated synapses, $\Theta^{-}$was assessed after the washout of LTP mechanisms. However, this washout cannot account for the opposite shifts in $\Theta^{-}$in depressed and potentiated synapses. Indeed, whether it occurred 10-20 min or $40 \mathrm{~min}$ (or later) after the beginning of the whole-cell recording, a pairing to $-40 \mathrm{mV}$ never modified synaptic transmission, whereas a pairing to $-30 \mathrm{mV}$ constantly produced LTD in naïve synapses. This indicates that $\Theta^{-}$remained stable at $V_{\mathrm{m}}=-40$ $\mathrm{mV}$ in naïve synapses and was not affected by LTP washout. Therefore, the shifts in $\Theta^{-}$to $V_{\mathrm{m}}=-20 \mathrm{mV}$ in depressed synapses (Fig. 5) and to $V_{\mathrm{m}}=-50 \mathrm{mV}$ in potentiated synapses (Fig. 6) were triggered by previous synaptic activity. This conclusion is further supported by the evidence that, as the shift in $\Theta+$ to a more polarized $V_{\mathrm{m}}$ in depressed synapses, the shift in $\Theta^{-}$to a more polarized $V_{\mathrm{m}}$ in potentiated synapses was also input-specific.

The most prominent theoretical model that relates directly to metaplasticity is the Bienenstock, Cooper, and Munro model (BCM model) of experience-dependent visual cortical plasticity (Bienenstock et al., 1982). A key feature of this model is that the value of $\Theta_{\mathrm{m}}$, the LTD-LTP crossover point, increases after a period of increased activity, promoting synaptic depression and inhibiting synaptic potentiation, and decreases after a period of decreased activity, facilitating synaptic potentiation and inhibiting synaptic depression. Our finding that $\Theta^{+}$, equivalent to $\Theta_{\mathrm{m}}$, decreases in depressed synapses provides experimental support for the concept that $\Theta_{\mathrm{m}}$ varies. However, the changes in the voltage-response function for the induction of LTD and LTP are better accounted for if we consider the concomitant variations of a second point: $\Theta^{-}$, the $V_{\mathrm{m}}$ above which LTD is generated (Artola et al., 1990; Artola and Singer, 1993) (Fig. 7). In depressed synapses, $\Theta^{-}$and $\Theta^{+}$move toward each other, facilitating the induction of LTP and completely abolishing LTD induction. Conversely, in potentiated synapses, $\Theta^{-}$moves toward more polarized $V_{\mathrm{ms}}$, facilitating LTD induction. Although not shown, it is likely that $\Theta^{+}$moves simultaneously toward more depolarized $V_{\mathrm{ms}}$. The facilitation of LTD induction in potentiated synapses would thus be achieved through both a decrease in $\Theta^{-}$and an increase in $\Theta^{+}$. Indeed, stimulation patterns that facilitate subsequent LTD induction are also effective in inhibiting LTP induction (Fujii et al., 1991; Christie and Abraham, 1992; Christie et al., 1995). Furthermore, both LFS, which has little or no effect (Barrionuevo et al., 1980; Staubli and Lynch, 1990; Fujii et al., 1991; Larson et al., 1993; Wexler and Stanton, 1993; Bortolotto et al., 1994; O'Dell and Kandel, 1994; Wagner and Alger, 1995; Norris et al., 1996), and tetani, which produce LTP (Yang and Faber, 1991), can subsequently induce LTD. It is interesting to note that similar decrease in $\Theta^{-}$and increase in $\Theta^{+}$has been proposed to account for the effect of stress and glucocorticoid receptor activation on synaptic plasticity (Coussens et al., 1997).

Variations of the voltage-response function for the induction of LTD and LTP result from the concomitant shifts in the voltages for eliciting LTD and LTP in opposite directions. These shifts appear to be time-dependent. We measured the variations in the voltages for eliciting LTD and LTP between 7-10 min and 30-40 min after the conditioning pairing, therefore, well within the reported durations of LTD facilitation (Fujii et al., 1991; Christie and Abraham, 1992; Holland and Wagner, 1998) (but see Wang et al., 1998) and LTP inhibition (Huang et al., 1992; Abraham and Huggett, 1997) (but see Frey et al., 1995). These shifts are synapse-specific. As the facilitation of LTD (Christie and Abraham, 1992; Wexler and Stanton, 1993) (but see Holland and Wagner, 1998) and the inhibition of LTP (Huang et al., 1992; Abraham and Huggett, 1997) by previous synaptic activity, the shifts in $\Theta^{+}$in depressed synapses and in $\Theta^{-}$in potentiated ones were input-specific. These shifts are triggered by postsynaptic mechanisms. Because they are in opposite directions, they rather involve a broad range of signal transduction processes, such as CaMKII (Mayford et al., 1995), PKC (Wang et al., 1998), and phospholipase C (Cohen et al., 1998) (for review, see Abraham and Bear, 1996; Abraham and Tate, 1997). The metaplastic processes described here do not seem to be the only mechanisms for activity-dependent modulation of subsequent synaptic plasticity. In the developing visual cortex, visual experience shifts the frequency-response function for the production of LTD and LTP (Kirkwood et al., 1996). This variation requires for synapses to be activated during long time periods and are likely related to irreversible changes in NMDA receptor-gated channel properties (Carmignoto and Vicini, 1992; Hestrin, 1992).

\section{REFERENCES}

Abraham WC, Bear MF (1996) Metaplasticity: the plasticity of synaptic plasticity. Trends Neurosci 19:126-130.

Abraham WC, Huggett A (1997) Induction and reversal of long-term potentiation by repeated high-frequency stimulation in rat hippocampal slices. Hippocampus 7:137-145.

Abraham WC, Tate WP (1997) Metaplasticity: a new vista across the field of synaptic plasticity. Prog Neurobiol 52:303-323.

Artola A, Singer W (1993) Long-term depression of excitatory synaptic transmission and its relationship to long-term potentiation. Trends Neurosci 16:480-487.

Artola A, Bröcher S, Singer W (1990) Different voltage-dependent thresholds for inducing long-term depression and long-term potentiation in slices of rat visual cortex. Nature 347:69-72.

Barrionuevo G, Schottler F, Lynch G (1980) The effects of repetitive low frequency stimulation on control and "potentiated" synaptic responses in the hippocampus. Life Sci 27:2385-2391.

Bienenstock EL, Cooper LN, Munro PW (1982) Theory for the development of neuron selectivity: orientation specificity and binocular interaction in visual cortex. J Neurosci 2:32-48.

Bolshakov VY, Siegelbaum SA (1994) Postsynaptic induction and presynaptic expression of hippocampal long-term depression. Science 264:1148-1152. 
Bortolotto ZA, Bashir ZI, Davies CH, Collingridge GL (1994) A molecular switch activated by metabotropic glutamate receptors regulates induction of long-term potentiation. Nature 368:740-743.

Carmignoto G, Vicini S (1992) Activity-dependent decrease in NMDA receptor-responses during development of the visual cortex. Science 258:1007-1011.

Christie BR, Abraham WC (1992) Priming of associative long-term depression in the dentate gyrus by è frequency synaptic activity. Neuron 8:79-84.

Christie BR, Stellwagen D, Abraham WC (1995) Evidence for common expression mechanisms underlying heterosynaptic and associative longterm depression in the dentate gyrus. J Neurophysiol 74:1244-1247.

Coan EJ, Irving AJ, Collingridge GL (1989) Low frequency activation of the NMDA receptor system can prevent the induction of LTP. Neurosci Lett 105:205-210.

Cohen A, Abraham WC (1996) Facilitation of long-term potentiation by prior activation of metabotropic glutamate receptors. J Neurophysiol 76:953-962.

Cohen AS, Raymond CR, Abraham WC (1998) Priming of long-term potentiation induced by activation of metabotropic glutamate receptors coupled with phospholipase C. Hippocampus 8:160-170.

Coussens CM, Kerr DS, Abraham WC (1997) Glucocorticoid receptor activation lowers the threshold for NMDA-receptor-dependent homosynaptic long-term depression in the hippocampus through activation of voltage-dependent calcium channels. J Neurophysiol 78:1-9.

Cummings JA, Mulkey RM, Nicoll RA, Malenka RC (1996) $\mathrm{Ca}^{2+}$ signaling requirements for long-term depression in the hippocampus. Neuron 16:825-833.

Deisseroth K, Bito H, Tsien RW (1996) Signaling from synapse to nucleus: postsynaptic CREB phosphorylation during multiple forms of hippocampal synaptic plasticity. Neuron 16:89-101.

Dudek SM, Bear MF (1992) Homosynaptic long-term depression in area CA1 of hippocampus and effects of $N$-methyl-D-aspartate receptor blockade. Proc Natl Acad Sci USA 89:4363-4367.

Dudek SM, Bear MF (1993) Bidirectional long-term modification of synaptic effectiveness in the adult and immature hippocampus. J Neurosci 13:2910-2918.

Dunwiddie T, Lynch G (1978) Long-term potentiation and depression of synaptic responses in the rat hippocampus: localization and frequency dependency. J Physiol (Lond) 276:353-367.

Fitzsimonds RM, Song H-J, Poo M-M (1997) Propagation of activitydependent synaptic depression in simple neural networks. Nature 388:439-448.

Frey U, Schollmeier K, Reymann KG, Seidenbecher T (1995) Asymptotic hippocampal long-term potentiation in rats does not preclude additional potentiation at later phases. Neuroscience 67:799-807.

Fujii S, Saito K, Miyakawa H, Ito K, Kato H (1991) Reversal of longterm potentiation (depotentiation) induced by tetanus stimulation of the input to CA1 neurons of guinea pig hippocampal slices. Brain Res 555:112-122.

Goda Y, Stevens CF (1996) Long-term depression properties in a simple system. Neuron 16:103-111.

Hestrin S (1992) Developmental regulation of NMDA receptormediated synaptic currents at a central synapse. Nature 357:686-689.

Heynen AJ, Abraham WC, Bear MF (1996) Bidirectional modification of CA1 synapses in the adult hippocampus in vivo. Nature 381:163-166.

Holland LL, Wagner JJ (1998) Primed facilitation of homosynaptic long-term depression and depotentiation in rat hippocampus. J Neurosci 18:887-894.

Huang Y-Y, Colino A, Selig DK, Malenka RC (1992) The influence of prior synaptic activity on the induction of long-term potentiation. Science 255:730-733.

Izumi Y, Clifford DB, Zorumski CF (1992a) Low concentrations of $\mathrm{N}$-methyl-D-aspartate inhibit the induction of long-term potentiation in rat hippocampal slices. Neurosci Lett 137:245-248.

Izumi Y, Clifford DB, Zorumski CF (1992b) Inhibition of long-term potentiation by NMDA-mediated nitric oxide release. Science 257:1273-1276.

Kamal A, Ramakers GMJ, Urban IJA, De Graan PNE, Gispen WH (1999) Chemical LTD in the CA1 field of the hippocampus from young and mature rats. Eur J Neurosci 11:3512-3516.

Kandler K, Katz LC, Kauer JA (1998) Focal photolysis of caged glutamate produces long-term depression of hippocampal glutamate receptors. Nature Neurosci 1:119-123.

Kerr DS, Abraham WC (1995) Cooperative interactions among afferents govern the induction of homosynaptic LTD in the hippocampus. Proc Natl Acad Sci USA 92:11637-11641.

Kirkwood A, Dudek SM, Gold JT, Aizenman CD, Bear MF (1993) Common forms of synaptic plasticity in the hippocampus and neocortex in vitro. Science 260:1518-1521.

Kirkwood A, Rioult MG, Bear MF (1996) Experience-dependent modification of synaptic plasticity in visual cortex. Nature 381:526-528.

Larson J, Xiao JP, Lynch G (1993) Reversal of LTP by theta frequency stimulation. Brain Res 600:97-102.

Linden DJ (1994) Long-term synaptic depression in the mammalian brain. Neuron 12:457-472.

Manahan-Vaughan D (1997) Group 1 and 2 metabotropic glutamate receptors play differential roles in hippocampal long-term depression and long-term potentiation in freely moving rats. J Neurosci 17:3303-3311.

Mayford M, Wang J, Kandel ER, O'Dell TJ (1995) CaMKII regulates the frequency-response function of hippocampal synapses for the production of both LTD and LTP. Cell 81:891-904.

Mulkey RM, Malenka RC (1992) Mechanisms underlying induction of homosynaptic long-term depression in area CA1 of the hippocampus. Neuron 9:967-975.

Nicoll RA, Malenka RC (1995) Contrasting properties of two forms of long-term potentiation in the hippocampus. Nature 377:115-118.

Norris CM, Korol DL, Foster TC (1996) Increased susceptibility to induction of long-term depression and long-term potentiation reversal during aging. J Neurosci 16:5382-5392.

O'Dell TJ, Kandel ER (1994) Low-frequency stimulation erases LTP through an NMDA receptor-mediated activation of protein phosphatases. Learn Mem 1:129-139.

Oliet SHR, Malenka RC, Nicoll RA (1997) Two distinct forms of longterm depression coexist in CA1 hippocampal pyramidal cells. Neuron 18:969-982.

Sejnowski TJ (1977) Storing covariance with nonlinearly interacting neurons. J Math Biol 4:303-321.

Staubli U, Lynch G (1990) Stable depression of potentiated synaptic responses in the hippocampus with $1-5 \mathrm{~Hz}$ stimulation. Brain Res 513:113-118.

Stevens CF, Wang Y (1994) Changes in reliability of synaptic function as a mechanism for plasticity. Nature 371:704-707.

Wagner JJ, Alger BE (1995) GABAergic and developmental influences on homosynaptic LTD and depotentiation in rat hippocampus. J Neurosci 15:1577-1586.

Wang Y, Rowan MJ, Anwyl R (1996) Evidence that long-term depression induction in the rat hippocampus in vitro requires $\mathrm{Ca}^{2+}$ influx via $\mathrm{Ni}^{2+}$-sensitive $\mathrm{Ca}^{2+}$ channels and $\mathrm{Ca}^{2+}$ release from intracellular stores. J Physiol (Lond) 495:50P.

Wang Y, Wu J, Rowan MJ, Anwyl R (1998) Role of the protein kinase $\mathrm{C}$ in the induction of homosynaptic long-term depression by brief low frequency stimulation in the dentate gyrus in the rat hippocampus in vitro. J Physiol (Lond) 513.2:467-475.

Wexler EM, Stanton PK (1993) Priming of homosynaptic long-term depression in hippocampus by previous synaptic activity. NeuroReport 4:591-594.

Yang X-D, Faber DS (1991) Initial synaptic efficacy influences induction and expression of long-term changes in transmission. Proc Natl Acad Sci USA 88:4299-4303. 